\title{
Marin Laak
}

\section{KREUTZWALDI SAJANDI DIGITAALARHIIV}

Digitaalne keskkond ja internet ning sellega kaasnevad uued kultuuritarbimise harjumused ei ole jätnud puudutamata ka kultuuriloolise pärandi uurijaid. Kirjandusajaloolaste ette on kerkinud küsimus, kuidas säilib või muutub kirjanduslik-kultuuriline järjepidevus uues keskkonnas. Missugused digitaalse keskkonna omadused ja arvutitehnoloogia võimalused võivad produktiivsed olla eesti kirjandusajaloo representeerimise seisukohast? Artiklis tutvustatakse kirjandus- ja kultuuriloo projekti SERVITI, mille eesmärgiks on olnud võimaluste otsimine digitaalse meedia ja vanema kirjandusloo sidumiseks. Praegune, arvutikultuuriga seonduv uue meedia ajajärk tingib ka kirjandusloo "ümbermõtlemise" või "uuestimõtlemise".

Nüüdisaegsete uue meedia kriitiliste diskussioonide keskmes on varasema ja digitaalse ajastu meedia erinevused, uued fenomenid kultuuri loomises, levimises ja tarbimises. Projekti SERVITI digitaalses keskkonnas teostamisele eelnenud metodoloogilistes alusuuringutes selgitati uue meedia kui uut tüüpi representatsioonikeskkonna tunnuseid eesmärgiga tuua esile võimalusi, mida tuleb arvestada ka eesti kirjandusloo mudelite konstrueerimisel. Võibki öelda, et tänapäevane elektrooniline meedia, internet ja digitaalkultuur ei ole kaasa toonud mitte ainult uut tüüpi kommunikatsioonimudeleid, sotsiaalseid praktikaid jne, vaid ka uue kirjaoskuse (new literacy) vajaduse, mille puhul peab rõhutama kahepoolset, kirjutamise ja vastuvõtu vaatepunkti. 
Projektid

Esimesel juhul, tekstide loomisega seotult, on keskseks mõisteteks muutunud mitte enam lehekülg, vaid ekraan ja v is u a a ls u s. "Uue kirjutamise" aluseks on "pildilisus", sealjuures käsitletakse pildina mitte ainult fotosid ja kujutava kunsti teoseid, vaid ka ekraani: see on organiseeritud visuaalse, mitte (trüki)lehekülje loogika alusel. Teiseks, vastuvõtu ja lugemise seisukohast rõhutatakse "kasutaja" kriitilise kirjaoskuse (critical literacy) vajalikkust. See teema on muutunud aktuaalseks aruteluobjektiks suuri andme- ja infohulki koondavate interaktiivsete ja hüpertekstuaalste võrgustikutaoliste tekstistruktuuride õpetamise vaatepunktist. On selge, et uue kirjaoskuse nõudmised on seotud teksti (kirjutamise) enese muutumisega digitaalkeskkonnas ja uute tingimuste tekkimisega nii tekstide loomisel kui ka tarbimisel.

Arvutitehnoloogia ja digitaalkeskkond on mõjutamas meie teadmusmudeleid ja mõtlemist ka siis, kui seoseid digitaalse uue meedia kultuuriga otseselt ei eeldatagi. Allpool kirjeldatava digitaalprojekti eellugu on seotud digitaalsele keskkonnale omaste mittelineaarsete tekstistruktuuride, seostevõrgustike ja visuaalkujundile rajatud kontseptsiooniga, mida esialgu püüti rakendada trükitehnika abil.

\section{Eellugu}

Projekti aluseks oli eesti rahvuseepose looja, Friedrich Reinhold Kreutzwaldi 200. sünnipäeva tähistanud Eesti Kirjandusmuuseumi rändnäitus Kreutzwaldi sajand. Kalevipoeg (2003). Rändnäituse kontseptsiooni aluseks oli kirjaniku elu ja loomingu markeerimine Eesti- ja Liivimaa 19. sajandi kultuuri ja olude ning kaasaegse Euroopa kirjandusprotsessi taustal kogu sajandit läbiva nelja ajatelje kaudu. See aga tingis vajaduse kasutada näituse stendil tavatult suurt materjalikogu ehk andmehulka: nii sõnalisi tekste kui ka pildimaterjale ajaloolistest isikutest, paikadest, hoonetest, trükistest jne. Kuivõrd rändnäituse kujundaja Peeter Laurits tegi oma tööd arvutigraafika programmiga, oli 
kõikide andmete paigutamine stendipinnale-ekraanile võimalik. Probleemiks osutus see uuenduslik vorm aga näituse külastajale. Tasapinnale laotatud tekstilisi kommentaare oli vaevarikas lugeda, erinevatel kõrgustel esitatud pildid mõjusid pigem lapitekimustri kui kommentaare täiendava tekstuaalse infona, nagu seda olid mõelnud näituse loojad. Seega mõjusid paralleelselt neljal tasandil esitatud andmed küll visuaalselt, kuid oli selge, et "lugejale" nendega lähema tutvumise võimaldamine eeldas elektroonilist andmekandjat.

Stendidel esitatud rändnäituse Kreutzwaldi sajand. Kalevipoeg digitaalsele kujule viimise projekt sai 2004. aasta kevadel nimeks SERVITI: Suure Eesti Rahvuseepose Virtuaal-InterTekstuaalne Illustratsioon. Projekti täitmise tulemustega võib tutvuda internetis (http:// kreutzwald.kirmus.ee).

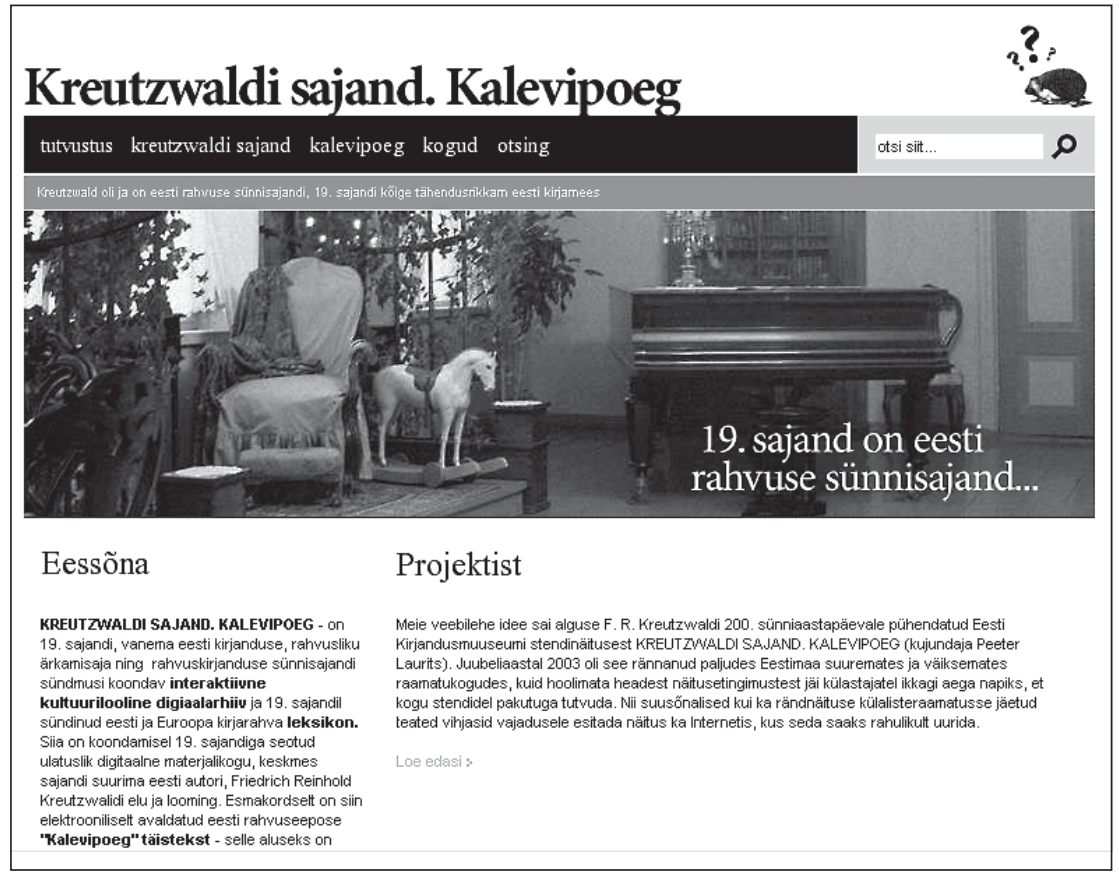

Foto 1. Digitaalnäituse Kreutzwaldi sajand. Kalevipoeg avalehekülg tekstiga "19. sajand on eesti rahvuse sünnisajand...” 
Projektid

\section{Kontseptsioon}

Projekti SERVITI keskseks ideeks on kirjaniku elu ja loomingu edasiandmine tema retseptsiooniajaloolises situatsioonis, st kontekstuaalsetes seostes tema kaasaegse Euroopa kirjanduse ning Eesti kirjanduse, kultuuri ja olustikuga.

Teiseks alusideeks on sellise digitaalse keskkonna loomine, mis võimaldaks näidata koos kirjaniku biograafiliste andm ete g a tema tekste, lehitseda raamatuid ja käsikirju, vaadata dokumente ja fotomaterjale ning liita hilisemad uurimuslikud tekstid - seega kirjanduslooliste allikate kättesaadavaks tegemine kasutajale.

Kolmandaks ideeks oli keskkonna loomine, mis võimaldaks siduda kirjanduslikku teksti (F. R. Kreutzwaldi Kalevipoja näitel) selle eel- ja järeltekstide, käsikirjade ning laiemas tähenduses intertekstuaalsete tekstidega kirjandusest kuni heli ja piltideni.

\section{Tehnoloogiline lahendus}

Projekti täitmise esimese kahe etapi (2004-2005) tulemused olid oodatust mitmekordselt laiemad, avades projekti tarkvara edasiarendamises uue perspektiivi. Kuigi esialgses projektis oli ette nähtud vaid näituse Kreutzwaldi sajand. Kalevipoeg internetilahenduseks vajaliku tarkvara loomine, pakkus projekti tehnoloogiline partner tarkvaraarendusfirma Laborint $^{1}$ välja lahenduse, mis muudab Kreutzwaldi sajandi üsna universaalseks mudeliks eesti kirjandus- ja kultuuriajaloo esitamisel arvutivõrgus.

Lahenduse keskmeks on dünaamilise ajatelje moodul, mis võimaldab esitada kultuurilooliste allikmaterjalide arvutiandmebaasi interaktiivse aegruumilise keskkonnana. Ajatelje aluseks on võetud rändnäituse formaalne, 19. sajandi raamistik (1800-1900), kuid see jääb põhimõtteliselt avatuks. Soovi korral saab ajatelge arendada nii va- 
nema ajaloo kui ka 21. sajandi suunas. Kuna programm on kergesti administreeritav, saab ajatelgedel esitatavat infot muuta, parandada ja täiendada, rääkimata arhiiviallikate ja kommenteerivate tekstide pideva lisamise võimalusest. Näiteks saab vastavate hüpermeedia materjalide ja andmete liitmisel näidata interdistsiplinaarseid seoseid kirjandusprotsessi ja sama perioodi kunsti-, muusika- ja teatriajaloo vahel. Sisu täiendamisel autoritutvustuste ja/või -ülevaadetega võiks lehekülg täita ka elektroonilise isikuleksikoni funktsiooni.

Nende ideede teostamiseks alustati stendinäituse Kreutzwaldi sajand. Kalevipoeg sisuarhitektuuri väljatöötamisega. Näitusematerjale struktureeriti esitamiseks kolme peamenüü - "Kreutzwaldi sajand", “Kalevipoeg” ja "Kogud” - kaudu.

\section{Peamenüü "Kreutzwaldi sajand"}

Siin avaneb dünaamilistel ajatelgedel 19. sajandi kultuuriline aegruum. Selle kaudu saab 19. sajandi sündmusi jälgida aasta-aastalt paralleelselt neljal tasandil.

Esimene ajatelg Kreutzwald sisaldab andmeid 19. sajandi eesti olulisema kirjaniku, F. R. Kreutzwaldi biograafia ja bibliograafia kohta.

Teine ajatelg Eesti elu markeerib tähtsamaid kultuuriajaloolisi fakte ja sündmusi 19. sajandi Eesti- ja Liivimaal: seadusloome, hariduse, tööstuse, maaelu ja ajakirjanduse areng ning sündmused ühiskondlikus elus ja rahvuslikus liikumises. Sündmuste andmebaas on leitav menüüst "Kogud".

Kolmas ajatelg Eesti kirjandus toob välja eesti kirjandusajaloolise protsessi eesti autorite ja nende kõige olulisemate teoste sünni- ja ilmumisaastate kaudu. Valiku aluseks on eesti kirjandusklassika ja formaalse kriteeriumina kirjaniku 19. sajandi piiresse jääv sünni- (või surma)kuupäev.

Neljas ajatelg Euroopa kirjandus toob välja Kreutzwaldi sajandi (peamiselt) Euroopa kirjanike eluaastad ja nende kõige olulisemate 


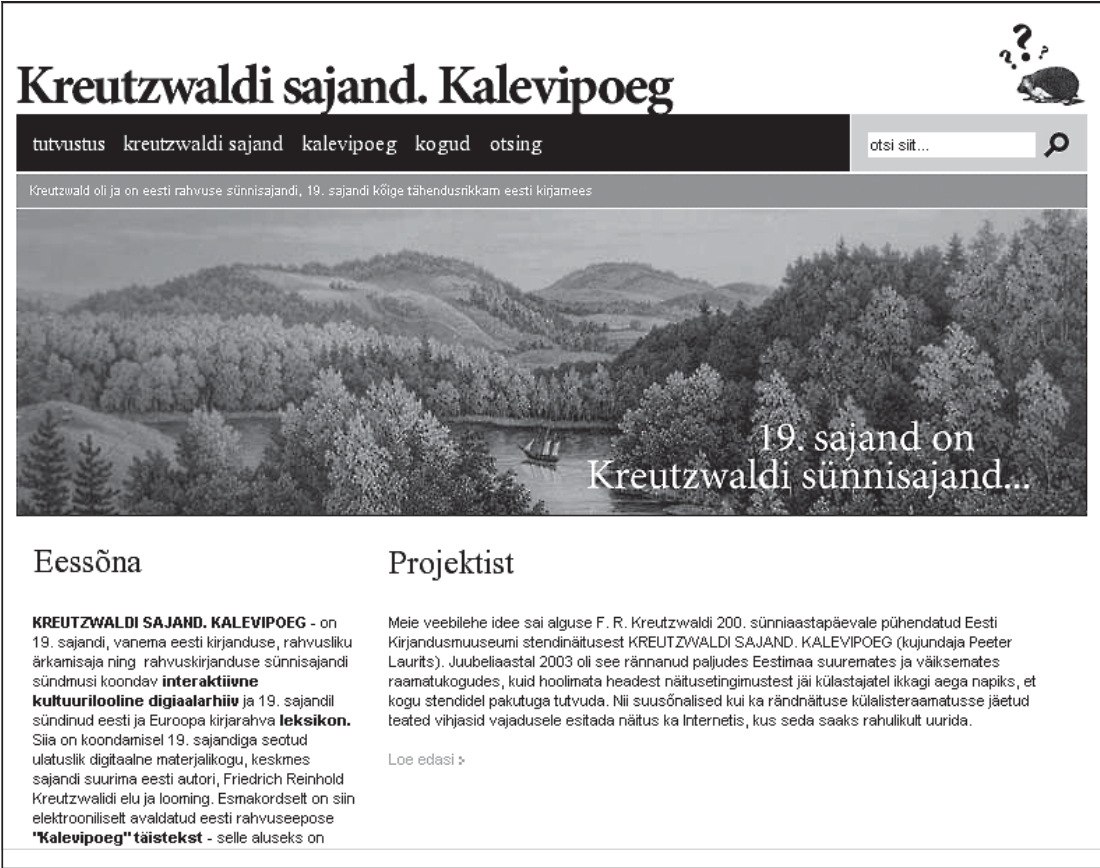

Foto 2. Digitaalnäituse Kreutzwaldi sajand. Kalevipoeg avalehekülg tekstiga "19. sajand on Kreutzwaldi sünnisajand..."

klassikaliste teoste ilmumise ajad. Sündmuste andmebaas on menüüs "Kogud". Eesti ja Euroopa kirjanike tutvustuste andmebaas on samuti leitav menüüst "Kogud".

\section{Peamenüü "Kalevipoeg”}

Menüü keskmes on F. R. Kreutzwaldi eeposega Kalevipoeg seotud materjalid, need on toodud punktide kaupa alljärgnevalt.

1. Ajatelg Kalevipoja saamislugu sisaldab rändnäituse Kreutzwaldi sajand kataloogis Kreutzwald. Missioon. Tegelikkus² esitatud kommenteerivaid tekste eepose sünniloo kohta. Tutvustatakse rahvuseepose loomise idee kujunemist Balti estofiilide seas alates 19. sajandi algusest, F. R. Faehlmanni ja F. R. Kreutzwaldi osa eepose kir- 
jutamisel, eepose tsensuuri ja trükkimisega seotud raskusi jm (autor Kristi Metste).

2. Kalevipoja esimene tekstiversioon sisaldab esiteks rariteetse käsikirja Alg-Kalevipoeg (1853) digitaalse publikatsiooni (piltidena) ja teiseks selle trükikoopia elektroonilist tekstiversiooni. Käsikiri avaneb projekti SERVITI tarbeks välja töötatud lehitsejas. Alg-Kalevipoja digiteerimine on seotud Eesti Kultuuriloolises Arhiivis alustatud kultuuripärandi digitaalsete kasutuskoopiate laiaulatusliku projekti ettevalmistamisega.

3. Eepose Kalevipoeg (1861) elektrooniline täistekst - viimase, 18. trüki (Tallinn: SE \& JS 2003) versiooni alusel. Eepose tekst on interaktiivne ning struktureeritud laulude ja allteemade kaupa. Programmi võimaluste markeerimiseks on näidatud hilisemate tekstikihistuste

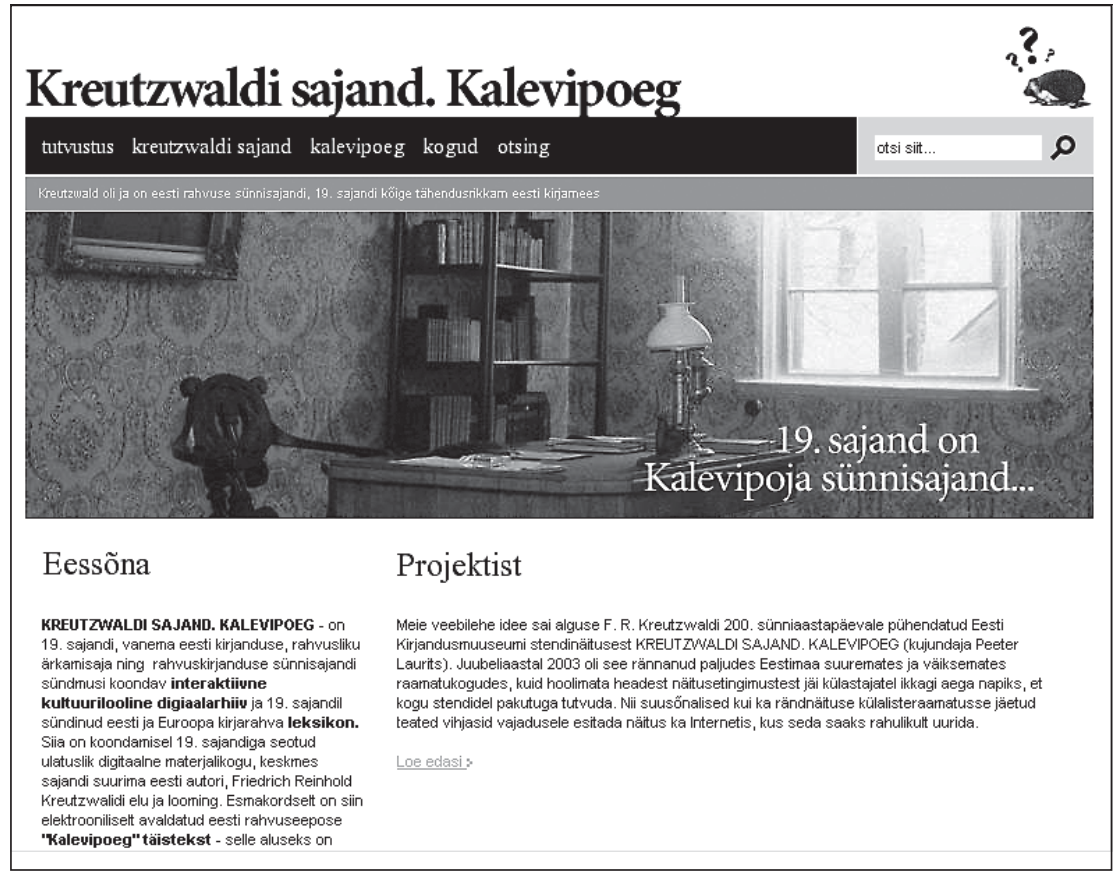

Foto 3. Digitaalnäituse Kreutzwaldi sajand. Kalevipoeg avalehekülg tekstiga "19. sajand on Kalevipoja sünnisajand...” 
Projektid

(luule, muusika jne) lisamise võimalus (vt näiteks "Soovituseks", "Kahekümnes lugu").

4. Eepost tutvustav rariteetne vanaraamat Lühikene seletus Kalevipoja laulude sisust (1869) - digitaalne publikatsioon (piltidena), avaneb lehitsejas. Raamatukese sisu saab võrrelda eepose esimese variandi ja trükiversiooniga: siin on F. R. Kreutzwald esitanud eepose laulude sisukokkuvõtted eestikeelse lugeja jaoks.

5. Rariteetsed väljaanded, Õpetatud Eesti Seltsi esimese ja viienda vihiku Kalewipoeg, eine Estnische Sage $(1857,1861)$ digitaalsed publikatsioonid. Nendele eesti- ja saksakeelsetele ning kommentaaridega varustatud Kalevipoja vihikutele määrati 1860. aastal Peterburi Teaduste Akadeemia auhind.

\section{Peamenüü "Kogud"}

Sisaldab kaheksat tüüpi andmeid ja digiteeritud materjale, koondades alammenüüde kaudu ajatelgedel esitatut:

1) 19. sajandiga seotud eesti ja Euroopa kirjanike tutvustuste andmebaas (kirjanike leksikon), valiku aluseks kirjaniku paiknemine ajateljel; koostatud projekti jaoks;

2) F. R. Kreutzwaldiga seotud pildiarhiiv Eesti Kultuuriloolise Arhiivi fotokogust;

3) isikuleksikonis leiduvate eesti kirjanike fotoarhiiv Eesti Kultuuriloolise Arhiivi fotokogust;

4) projekti fotoarhiivide alusel moodustatud temaatilised galeriid;

5) 19. sajandi sündmuste andmebaas;

6) F. R. Kreutzwaldi teoste digitaalraamatukogu (piltidena);

7) F. R. Kreutzwaldi ja Kalevipojaga seotud lingikogu;

8) F. R. Kreutzwaldi ja Kalevipojaga seotud uuemate uurimuste ja kriitika bibliograafia.

Seega on projektis SERVITI seotud kirjandus- ja kultuuriloolised allikmaterjalid ühtses digitaalses aegruumis, mis on struktureeritud 
nii temaatiliselt andmetüüpide kaudu kui ka ajatelje mooduli alusel. Üheks alusideeks on olnud kultuuripärandit säilitavate mäluasutuste digiteerimise eesmärkide rakendamine kultuuriajaloo esitamisel. Uue meedia keskkonna lisaväärtuseks (võrreldes trükimeediaga) on numbrilisest representatsioonist tulenev võimalus liita tervikuks suured andmehulgad ja tekstimassiivid. Projektis on otsitud F. R. Kreutzwaldi näitel lahendust kultuuriloolise arhiivi käsikirjade ja fotokogu ning arhiivraamatukogus säilitatavate rariteetsete trükiste digitaalsete kogude sidumiseks. Näiteks saab F. R. Kreutzwaldi eluloolistele andmetele lisaks näha pildigaleriisid kirjaniku perekonnaga seotud elupaikadest (Jõepere, Ohulepa ja Kaarli mõis, maja Võrus) ning tema kooliharidusega seotud linnade (Rakvere, Peterburi, Tartu, Paide) vaateid. Tutvuda võib mitmete käsikirjaliste arhiividokumentidega, mis on olnud aluseks eluloo kirjutamistel leksikonidest monograafiateni (Curriculum vitae, ristimistunnistus, ülikooli matrikkel, abielutunnistus jm). Ajateljel Eesti elu näidatud sündmusi täiendavad kultuuriloolisest ja filmiarhiivist pärit fotovalim ja illustratsioonid 19. sajandi baltisaksa estofiilide krestomaatilistest teostest (Johann Christoph Petri Ehstland und die Ehsten oder historisch-geographischstatistisches Gemälde von Ehstland (1802) ja Garlieb Helwig Merkeli Die Letten, vorzüglich in Liefland am Ende des philosophischen Jahrhunderts (1800)). Projekti tulemused tõestavad veel kord, et digitaalne vorm võimaldab traditsioonilist kirjandusajaloo esitust teiste tekstitasanditega piiramatult täiendada.

\section{Kokkuvõtteks}

Digitaalse meedia kriitikas on jõutud seisukohale, et vormilisest küljest põhineb kogu internetikultuur varasemate kultuurivormide selektsioonil, mitte uute loomisel. Arvutitehnoloogia areng rajaneb kultuuriliselt tuntud vormide kopeerimisel uues keskkonnas: kultuuris aastatuhandeid ja -sadu eksisteerinud traditsiooni modifitseerimi- 
Projektid

sel. Digitaalse uue meedia ja internetikeskkonna konstrueeritavus pakub intrigeerivaid väljavaateid mineviku, sealhulgas kirjandusajaloo uurimisel ja representeerimisel: võimaluse visualiseerida kirjandusajalugu interdistsiplinaarseste kontekstide ja kultuurilooliste allikmaterjalide kaudu.

Projekti SERVITI tulemuseks on stendinäituse Kreutzwaldi sajand. Kalevipoeg esitamine interneti vahendusel kättesaadava digitaalarhiivina. Eesti rahvuseepose Kalevipoeg looja F. R. Kreutzwaldi elu ja loomingut võib jälgida 19. sajandi Eesti- ja Liivimaa oludes, kuid ka Euroopa kultuuripildi osana. Sellist võimalust toetab metatasandil uuemate kriitiliste käsitluste bibliograafia. Rariteetsete käsikirjaliste arhiivimaterjalide, vanaraamatukogude ning pildi- ja fotomaterjalide sirvimiseks on välja töötatud kasutajasõbralik interaktiivne lehitseja. Kreutzwaldi sajandi materjalide tõlkimisel inglise keelde avaneks selle projekti kaudu võimalus tutvustada vanemat eesti kirjanduskultuuri ka väljapoole eesti keeleruumi.

Projekti kaks esimest etappi on teostatud Eesti Kultuuriministeeriumi toetusel. Selle edasiarendus näeb ette eesti vanema kirjandusloo (kuni Eesti Vabariigi loomiseni 1918) digitaalses keskkonnas rakendatava mudeli väljatöötamist riikliku programmi Eesti keel ja rahvuslik mälu rahastusel (2006-2008). ${ }^{3}$ Projekti SERVITI laiemaks eesmärgiks on eesti kirjanduse ja kultuuri ajaloo esitamiseks sobiva universaalse tarkvaralahenduse väljatöötamine.

\section{Kommentaarid}

${ }^{1}$ Vt http://www.laborint.com (6. juuni 2006).

${ }^{2}$ Laak, Marin \& Metste, Kristi (koost). Kreutzwald. Missioon. Tegelikkus: Kommentaarid F. R. Kreutzwaldi 200. sünniaastapäevale pühendatud näitusele "Kreutzwaldi sajand. Kalevipoeg". Tartu: Eesti Kirjandusmuuseum 2003.

${ }^{3}$ Projekt Kultuuriajaloo interaktiivne digitaalarhiiv ärkamisajast kuni Eesti Vabariigi loomiseni. 


\section{VÕIM \& KULTUUR 2}

\section{Koostaja ja toimetaja Mare Kõiva}

http://www.folklore.ee/pubte/eraamat/voimjakultuur2/

Koostaja ja toimetaja: Mare Kõiva

Keeletoimetaja: Mare Kalda

Inglise keele toimetaja: Tiina Kirss

Makett ja kaas: Alo Paistik

Pilditöötlus: Andres Kuperjanov

HTML: Diana Kahre

ISBN 978-9949-586-83-7 (pdf)

ISBN 978-9949-418-53-4 (trükis)

DOI: $10.7592 / \mathrm{VK} 2.2006$

Tartu 2018

Trükis ilmunud: Võim \& kultuur 2. Koostaja ja toimetaja

Mare Kõiva. Võim ja kultuur. Tartu 2006

E-raamatu valmimist toetas: EKKM14-344 Eesti keele, kultuuri ja folkloori kasutusalade laiendamine ja tutvustamine elektroonilistel infokandjatel.
(C) 2018 Eesti Kirjandusmuuseum
(C) 2018 Eesti Folkloori Instituut
(c) 2018 EKM FO rahvausundi ja meedia töörühm
(C) 2018 autorid 